\title{
A research on antioxidant activity evaluation of waste lignocellulosic biomass: optimization using response surface methodology
}

\author{
Bahar MERYEMOĞLU ${ }^{1 *}$ (D), Burcak KAYA ÖZSEL ${ }^{2}$ (D) Berna NIS ${ }^{2}$ (D) \\ ${ }^{1}$ Central Research Laboratory, University of Cukurova, Adana, Turkey \\ ${ }^{2}$ Department of Chemistry, Bursa Technical University, Bursa, Turkey
}

\begin{abstract}
In the present study, lignocellulosic biomass such as corn straw and sorghum were used as raw materials for a new, abundant, low-cost and natural antioxidant source to use in foods or medicinal materials as replacements for synthetic antioxidants such as butylated hydroxyanisole (BHA) and butylated hydroxytoluene (BHT). The effect of extraction temperature, extraction time, solvent volume on extraction yield, total phenol content and antioxidant activity were investigated and the results obtained by response surface methodology (RSM) were evaluated. Linear and quadratic models were revealed as a result of experiments. The fit of these models with predictions results were tested and optimal condition parameters were investigated. It was seen that different results were obtained because of structural differences between corn straw and sorghum. These results showed that the extraction temperature was the main positive linear effect on extraction yield. The solvent volume and temperature were found to important model terms for total phenol content. For antioxidant activity, the solvent volume was the main linear effect for sorghum where as it has a quadratic effect for corn straw biomass.
\end{abstract}

\section{Article info \\ History:}

Received:21.01.2020

Accepted:18.04.2020

Keywords:

Lignocellulosic

biomass,

phenolics,

antioxidant activity, response surface methodology, optimization.

\section{Introduction}

In recent years, hundreds of herbal sources have been tested for antioxidant activity. The most important natural antioxidant sources are plants (oilseeds, cereals, vegetables, fruits, spices), animal products (peptides, amino acids and carotenoids), enzymes (glutathione peroxidase, superoxide dismutase and catalase) and some microorganisms [1]. In addition, due to the fact that phenolic compounds are natural antioxidant sources and have positive effects on health, the interest in fruit and vegetable products is increasing day by day.

Phenolics, composed of one or more aromatic rings bearing one or more hydroxyl groups, are found in almost every vegetable and fruit. Despite their structural diversity they have similar properties so can basically be categorised into several classes. The favourable effects derived from phenolic compounds have been attributed to their antioxidant activity due to the their ability scavenge free radicals from the body [2]. Besides vegetables and fruits, agricultural lignocellulosic biomass could be interesting and low- cost natural sources of antioxidant phenolic compounds.

Lignocellulosic biomass composed of cellulose, hemicellulose, lignin and other extractives. These main extractives are aliphatic compounds (oils and waxes), terpenes (sterols and resins) and terpenoids, fatty acids, quinines, aldehydes, alcohols, coloring pigments, steroids and phenolic compounds [3]. Sorghum, as a lignocellulosic biomass, belongs to the Monocotyledon class of Gramine Familia. There are 113 species and represent over 40,000 genotypes [4]. It is the fifth most grown cereal plant in the world [5]. Sorghum is preferred due to the fact that high photosynthesis yield can easily be raised in all climatic conditions and does not require excessive irrigation and fertilizer. Corn, the industrial uses of which are very broad and generate large amounts of biomass residues. Corn straw production in 2014 was about $1661 \mathrm{Mt}$, highest among the three major types of crop straws (rice, wheat, corn) in the world [6]. Its chemical composition and low-cost make it an attractive feedstock to be used in production of high value products such as bioactive compounds. 
Studies on antioxidant activity are mainly focused on food in the human diet. Any study on lignocellulosic agro-wastes for antioxidant activityapplications have not been reported yet in the literature. Therefore, in this study sorghum and corn straw, as lignocellulosic biomass residue, were extracted and investigated for an alternative non-food cheap antioxidant sourcefor potential use in cosmetic, food and pharmaceutical industries.

Extraction is one of the most important step in antioxidant studies so effects of temperature, extraction time and solvent volume on extraction yield of phenolics from sorghum and corn straw were evaluated on the responses of total phenolic content and total antioxidant activity, optimal conditions were determined by using Response Surface Methodology (RSM).

\section{Experimental}

\subsection{Extraction of lignocellulosic biomass}

Sorghum and corn straw were used as biomass feedstocks. Sorgum was grown in Adana. It was harvested in autumn. The harvested plant was dried, grounded and used in extraction. Corn straw was obtained local supplier in Adana. The analytical data for lignocellulosic biomasses were given Table 1. The $7.5 \mathrm{~g}$ of grounded biomass was extracted with water:methanol (1:1) under reflux. After extraction, the solid residues were dried at $100^{\circ} \mathrm{C}$. The percentage of extraction was calculated as: (initial weight of biomass-weight of dried biomass)/(initial weight of biomass)*100.

UV-VIS Spectrophotometre: UV-1800 UV-VIS Spectrometer and UNICAM UV-VIS Spectrometer UV 2 pH meter: Adwa AD8000.

Table 1. Analytical data forlignocellulosicbiomasses.

\begin{tabular}{lcc}
\hline Analysis & \multicolumn{2}{c}{ wt \% } \\
\cline { 2 - 3 } & Sorghum & Cornstraw \\
\hline $\mathrm{C}$ & 39.75 & 47.80 \\
$\mathrm{H}$ & 5.22 & 6.89 \\
$\mathrm{~N}$ & 0.85 & 2.01 \\
$\mathrm{~S}$ & 0.11 & 0.48 \\
$\mathrm{O}$ & 54.07 & 34.76 \\
Moisture & 8.11 & 8.10 \\
Ash & 8.39 & 8.06 \\
Cellulose & 46.63 & 49.96 \\
Hemicellulose & 12.54 & 15.47 \\
Lignin & 18.95 & 15.09 \\
\hline
\end{tabular}

\subsection{Experimental design and optimization}

In this study the optimization approach provided by the Box-Behnken design (BBD, Design Expert 7.0.0). The effect of various factors include temperature, extraction time and solvent volume on the extraction of phenolics from lignocellulosic biomass were investigated. The effect of experimental parameters on extraction yield, total phenolic content and antioxidant activity was investigated by responce surface methodology (RSM). One of the greatest advantages of this method is to empirically demonstrate the effect of multiple experimental factors on the extraction efficiency by carrying out a few experimental studies. The 15 experimental run were carried out in this study. All experiment runs were carried out at least in duplicate. The range of factors used in the experimental run are given in Table 2.

Table 2. The ranges and levels of the factors in the experimental design

\begin{tabular}{lcccc}
\hline \multicolumn{1}{c}{ Factors } & Semb. & \multicolumn{3}{c}{ Ranges and Coded Levels } \\
& & $\mathbf{- 1}$ & $\mathbf{0}$ & $\mathbf{1}$ \\
\hline Temp. $\left({ }^{\circ} \mathrm{C}\right)$ & $\mathrm{A}$ & 60,00 & 80,00 & 100,00 \\
Solvent & $\mathrm{B}$ & 75,00 & 112,50 & 150,00 \\
volume $(1: 1)$ & & & & \\
mL & & & & \\
Time (min) & $\mathrm{C}$ & 30,00 & 45,00 & 60,00 \\
\hline
\end{tabular}

\subsection{Analysis}

Total phenolic content of extracts were determined by Folin-Ciocalteau assay [7]. 100 and $150 \mu$ L samples were mixed with $2.5 \mathrm{~mL}$ of 10 times diluted FolinCiocalteau reagent and $5 \mathrm{ml}$ of a $20 \%(\mathrm{w} / \mathrm{v})$ anhydrous sodium carbonate solution. The mixture was vortexed for $30 \mathrm{~s}$ and kept at room temperature for $2 \mathrm{~h}$. Absorbance at $760 \mathrm{~nm}$ was recorded using a UV-VIS spectrophotometer (Agilent-Cary60). Gallic acid was used as a standard for calibration curve. The total phenolic content was expressed as gallic acid equivalents (mg gallic acid/g biomass).

Antioxidant capacity analysis was performed immediately after extraction [8].Briefly, $1 \mathrm{mM}, 1.5 \mathrm{~mL}$ DPPH was mixed with 50 and $250 \mu \mathrm{L}$ sample solution and incubated for $105 \mathrm{~min}$ in dark covered with aluminum foil. Decrease of absorbance was monitored at $515 \mathrm{~nm}$ against a blank on a UV-VIS spectrometer (Agilent UV-Cary60). 
The percentage of inhibition was calculated by the following equation:

\section{Inhibition\% = (Absorbance of control-Absorbance of sample)/Absorbance of control X 100}

BHT (butylhydroxytoluene) was used as an antioxidant reference, inhibition percentage of sample was calculated using the graph by plotting BHT concentration against inhibition percentage and the results were gives as mg BHT equivalent/g biomass)

\section{Results and Discussion}

In this study, the extraction parametres such as extraction temperature, solvent volume and extraction time were applied for the extraction of corn straw and sorghum. The optimization model has been developed for the highest percentage of extraction, total phenoliccontent and antioxidant activity by applyinga 3-factor and 3-level Box-Behnken design (BBD).The variance analysis (ANOVA) was used to analyze data. The statistical significance of the quadratic effects of each factor on the responses was determined by using the Fischer (F-test) test at 95\% confidence level. It has been decided whether the proposed model is a fitting approach to the real response of the system, provided that the insignificant and regressing variation caused by "lack of fit" is significant at the $95 \%$ level of confidence. In addition, the fit of the model was tested using the regressionsquared $\left(\mathrm{R}^{2}\right)$, the adjusted $\mathrm{R}$ squared (Radj). Experimental design and responses of the dependent variables were given Table 3. And also, Table 4 shows variance analysis of responses.

\subsection{Model equation for the extraction yield}

As a result of experiments on the extraction of corn straw and sorghum which were made in accordance with experimental designs, the extraction yields were subjected to regression analysis and the following equations were obtained;

Extraction Yield (corn straw) $\mathrm{y}=+13.34+2.31 \mathrm{~A}+0.88 \mathrm{~B}-0.20 \mathrm{C}+7.500 \times 10$

${ }^{003} \mathrm{AB}+0.11 \mathrm{AC}+1.02 \mathrm{BC} \quad 2.04 \mathrm{~A}^{2}+0.096 \mathrm{~B}^{2}+0.57 \mathrm{C}^{2}$ (Eq.1)

Extraction Yield (sorghum) $\mathrm{y}=+16.81+1.28 \mathrm{~A}+0.16 \mathrm{~B}+0.068 \mathrm{C}+0.34 \mathrm{AB}+1.37 \mathrm{AC}+$ $0.31 \mathrm{BC}+0.46 \mathrm{~A}^{2}+0.37 \mathrm{~B}^{2}-0.62 \mathrm{C}^{2}$ (Eq. 2$)$

As can be seen in Eq.1, the positive value of coefficient A (2.31) indicates that the corn straw extraction yield increases with increasing the temperature from $60{ }^{\circ} \mathrm{C}$ to $100{ }^{\circ} \mathrm{C}$. The extraction temperature is the most significant parameter on extraction. While the B coefficient, solvent volume, was positive (0.88), indicating that the extraction yield increased with increasing the amount of solvent, the extraction time, $\mathrm{C}$, has a negative value $(-0.20)$ shows that the extraction yield will decrease with increasing time.

The fit of the model can be tested using the regression squared $\left(R^{2}\right)$. The values of $R^{2}$ and $R_{\text {adj }}$ found as a result of the variance analysis were 0.9328 and 0.8120 , respectively for corn straw. These values provides a suitable approach for the relationship between the independent variables and the extraction yield of the proposed equation. The values of $R^{2}$ and $R_{\text {adjwere }}$ 0.9264 and 0.7938 , respectively for sorghum. It was observed that all coefficients were positive and positively contributed to the sorghum extraction yield (Eq.2).
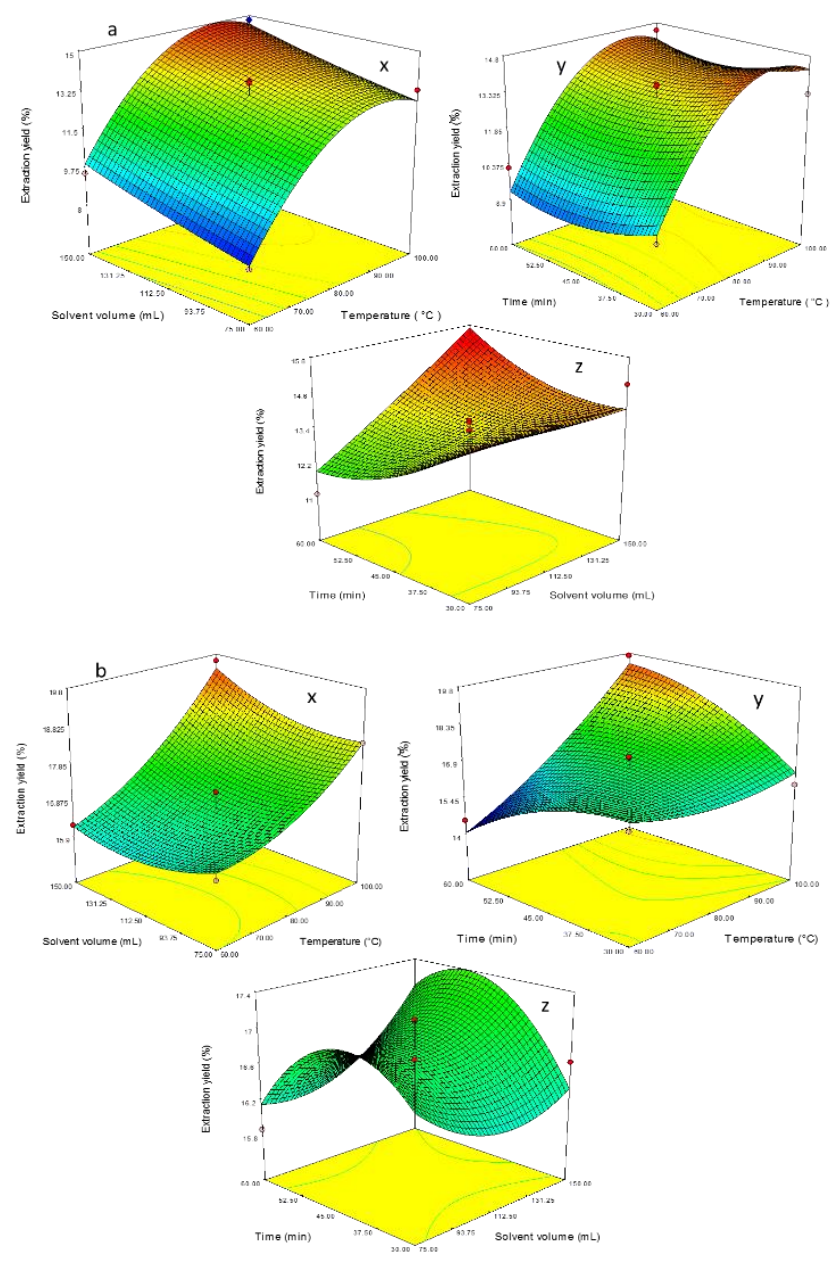

Fig.1. Response surface graphs for extraction yield a ) corn straw b) sorghum 
Meryemoğlu et al. / Cumhuriyet Sci. J., 41(3) (2020) 594-601

Table 3. Experimental design and responses of the dependent variables

\begin{tabular}{|c|c|c|c|c|c|c|c|c|c|c|c|c|c|c|}
\hline $\begin{array}{c}\text { Temperature } \\
\left({ }^{\circ} \mathrm{C}\right)\end{array}$ & $\begin{array}{l}\text { Solvent } \\
\text { volume } \\
(1: 1) \mathrm{mL}\end{array}$ & $\begin{array}{l}\text { Time } \\
(\mathrm{min})\end{array}$ & \multicolumn{4}{|c|}{$\begin{array}{c}\text { Corn Straw } \\
\text { Total phenol content }\end{array}$} & \multicolumn{2}{|c|}{ Antioxidant activity } & \multicolumn{2}{|c|}{ Extraction yield } & \multicolumn{2}{|c|}{$\begin{array}{c}\text { Sorghum } \\
\text { Total phenol content }\end{array}$} & \multicolumn{2}{|c|}{ Antioxidant activity } \\
\hline 80.00 & $\begin{array}{c}(1: 1) \mathrm{mL} \\
112.50\end{array}$ & 45.00 & $\begin{array}{c}\text { Actual } \\
13.59\end{array}$ & $\begin{array}{c}\text { Predicted } \\
13.34\end{array}$ & $\begin{array}{c}\text { Actual } \\
3.47\end{array}$ & $\begin{array}{c}\text { Predicted } \\
3.59\end{array}$ & $\begin{array}{l}\text { Actual } \\
2.15\end{array}$ & $\begin{array}{c}\text { Predicted } \\
2.42\end{array}$ & $\begin{array}{l}\text { Actual } \\
17.09\end{array}$ & $\begin{array}{c}\text { Predicted } \\
16.81\end{array}$ & $\begin{array}{c}\text { Actual } \\
7.53\end{array}$ & $\begin{array}{c}\text { Predicted } \\
8.16\end{array}$ & $\begin{array}{c}\text { Actual } \\
16.66\end{array}$ & $\begin{array}{c}\text { Predicted } \\
16.64\end{array}$ \\
\hline 80.00 & 75.00 & 30.00 & 14.88 & 14.35 & 2.73 & 3.06 & 1.85 & 1.97 & 17.16 & 16.64 & 6.35 & 6.92 & 11.33 & 14.24 \\
\hline 80.00 & 150.00 & 60.00 & 15.18 & 15.71 & 5.46 & 5.13 & 3.54 & 3.42 & 16.57 & 17.09 & 8.40 & 7.84 & 22.60 & 19.69 \\
\hline 60.00 & 112.50 & 60.00 & 10.24 & 9.25 & 3.16 & 3.19 & 2.90 & 2.99 & 14.55 & 14.06 & 6.64 & 6.75 & 8.88 & 10.91 \\
\hline 80.00 & 75.00 & 60.00 & 11.09 & 11.90 & 2.48 & 2.50 & 1.44 & 1.29 & 15.86 & 16.15 & 5.83 & 6.09 & 6.27 & 6.14 \\
\hline 100.00 & 75.00 & 45.00 & 13.28 & 12.82 & 2.42 & 2.12 & 1.52 & 1.49 & 18.39 & 18.42 & 6.53 & 6.07 & 4.23 & 3.35 \\
\hline 60.00 & 75.00 & 45.00 & 8.04 & 8.21 & 2.11 & 2.06 & 1.61 & 1.67 & 16.34 & 16.53 & 5.45 & 5.09 & 6.42 & 4.52 \\
\hline 80.00 & 112.50 & 45.00 & 13.67 & 13.34 & 3.64 & 3.59 & 2.69 & 2.42 & 16.25 & 16.81 & 8.59 & 8.16 & 17.32 & 16.64 \\
\hline 60.00 & 112.50 & 30.00 & 9.51 & 9.87 & 2.52 & 2.24 & 2.57 & 2.39 & 16.34 & 16.66 & 6.77 & 6.57 & 7.86 & 6.85 \\
\hline 100.00 & 150.00 & 45.00 & 14.77 & 14.60 & 4.52 & 4.57 & 2.91 & 2.85 & 19.61 & 19.41 & 8.64 & 9.01 & 6.92 & 8.82 \\
\hline 100.00 & 112.50 & 60.00 & 14.46 & 14.10 & 2.95 & 3.23 & 2.16 & 2.34 & 19.69 & 19.36 & 6.76 & 6.96 & 4.55 & 5.56 \\
\hline 100.00 & 112.50 & 30.00 & 13.28 & 14.27 & 3.65 & 3.62 & 2.80 & 2.71 & 16.00 & 16.49 & 9.85 & 9.75 & 11.78 & 9.75 \\
\hline 80.00 & 150.00 & 30.00 & 14.89 & 14.07 & 4.02 & 4.00 & 2.39 & 2.54 & 16.63 & 16.33 & 9.88 & 9.62 & 11.58 & 11.71 \\
\hline 60.00 & 150.00 & 45.00 & 9.50 & 9.96 & 2.90 & 3.20 & 2.97 & 3.00 & 16.20 & 16.17 & 6.14 & 6.60 & 9.20 & 10.08 \\
\hline 80.00 & 112.50 & 45.00 & 12.77 & 13.34 & 3.65 & 3.59 & 2.41 & 2.42 & 17.10 & 16.81 & 8.36 & 8.16 & 15.95 & 16.64 \\
\hline
\end{tabular}

Table 4. The variane analysis of responses

\begin{tabular}{|c|c|c|c|c|c|c|c|}
\hline & Responses & $\begin{array}{l}\text { Sum of } \\
\text { Squares }\end{array}$ & $\mathrm{df}$ & $\begin{array}{l}\text { Mean } \\
\text { Square }\end{array}$ & F Value & $\begin{array}{l}\text { P Value } \\
\text { Prob }>\text { F }\end{array}$ & \\
\hline \multirow[t]{2}{*}{ Corn straw } & Extraction yield & 71.03 & 9 & 7.89 & 7.72 & 0.0183 & significant \\
\hline & $\begin{array}{l}\text { TPC } \\
\text { BHT }\end{array}$ & $\begin{array}{l}10.58 \\
4.85\end{array}$ & $\begin{array}{l}9 \\
9\end{array}$ & $\begin{array}{l}1.18 \\
0.54\end{array}$ & $\begin{array}{l}10.11 \\
8.94\end{array}$ & $\begin{array}{l}0.0101 \\
0.0133\end{array}$ & $\begin{array}{l}\text { significant } \\
\text { significant }\end{array}$ \\
\hline \multirow[t]{2}{*}{ Sorghum } & Extraction yield & 24.66 & 9 & 2.74 & 6.99 & 0.0227 & significant \\
\hline & $\begin{array}{l}\text { TPC } \\
\text { BHT }\end{array}$ & $\begin{array}{l}25.92 \\
359.38\end{array}$ & $\begin{array}{l}9 \\
9\end{array}$ & $\begin{array}{l}2.88 \\
39.93\end{array}$ & $\begin{array}{l}6.58 \\
5.40\end{array}$ & $\begin{array}{l}0.0258 \\
0.0389\end{array}$ & $\begin{array}{l}\text { significant } \\
\text { significant }\end{array}$ \\
\hline
\end{tabular}


Response surface plots showing the effect of factors on extraction yield of corn straw and sorghum biomasspresented in Fig.1 a and Fig.1b. The interaction between solvent volume and extraction temperature at constant extraction time has a significant linear positive effect on corn straw extraction (Fig.1.a.x). It was determined that the extraction yield of corn straw increased with increasing temperature. Similarly, when the effect of extraction time and temperature variables were examined, it was observed that the extraction time was not effective but the temperature was an important factor on the extraction yield of corn straw (Fig 1.a.y). It has been found that maximum extraction yield will be achieved due to decrease in extraction time at constant temperature (Fig 1.a.z). As presented Fig.1.b.x, it was found that the temperature was an important factor for sorghum extraction yield and the solvent volume was not a significant factor on the sorghum extraction yield. Fig.1.b.y shows the relationship between the extraction time and the temperature, it was observed that the sorghum extraction yield decreased due to the increase in the extraction time. It was seen that the maximum values for the extraction yield of sorghum was obtained when the time was 45-50 minutes, when the solvent volume was generally high at constant temperature.

\subsection{Model equation for Total Phenolic Content (TPC)}

The model equation for total phenolic content (TPC) obtained from the extractions of corn straw and sorghum show the total phenolic content (phenolic acids, polyphenols and flavonoids) value as a function of temperature, extraction time and solvent volume. The equations of the model are given below:

TPC (corn straw)

$\mathrm{y}=\quad+3.59+0.36 \mathrm{~A}+0.89 \mathrm{~B}+0.14 \mathrm{C}+0.33 \mathrm{AB}-$ $0.33 \mathrm{AC}+0.42 \mathrm{BC}-0.60 \mathrm{~A}^{2}+1.667 \times 10^{-003} \mathrm{~B}^{2}+0.084 \mathrm{C}^{2}$ (Eq.3)

$\mathrm{TPC}_{\text {(sorghum) }}$ $\mathrm{y}=+8.16+0.85 \mathrm{~A}+1.11 \mathrm{~B}-0.65 \mathrm{C}+0.36 \mathrm{AB}-0.74 \mathrm{AC}-$ $0.24 \mathrm{BC}-0.79 \mathrm{~A}^{2}-0.68 \mathrm{~B}^{2}+0.13 \mathrm{C}^{2}$ (Eq.4)

The $\mathrm{R}^{2}$ and $\mathrm{R}_{\mathrm{adj}}$ values of total phenolic content models of corn straw and sorghum extracts were 0.9229 and 0.8541 for corn straw and 0.9222 and 0.7821 for sorghum, respectively. When the model for corn straw was examined, it was observed temperature and solvent volume are significant model terms (Eq.3). The temperature and the solvent volume as well as the extraction time were found to be important model terms for sorghum (Eq.4).

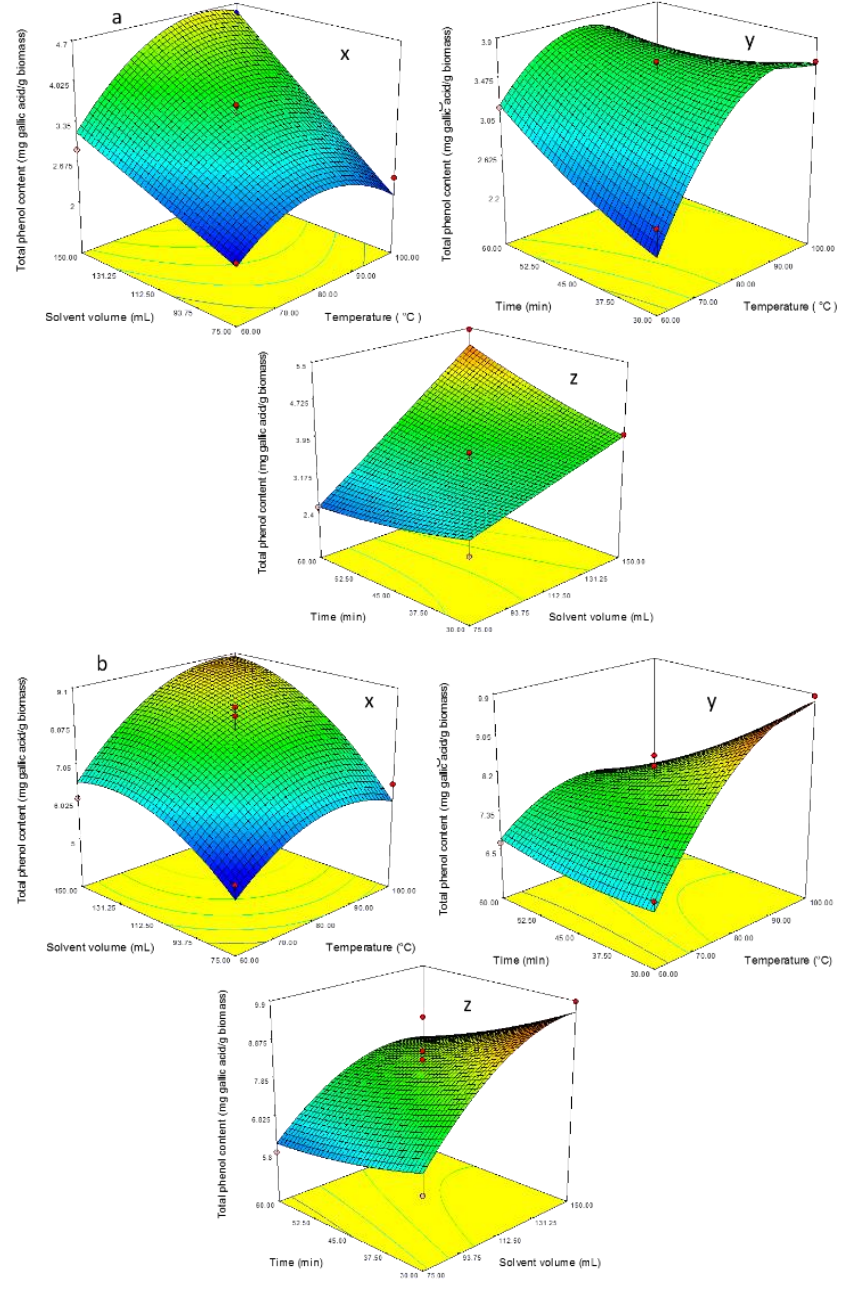

Fig. 2. Response surface graphs for total phenolic content a) corn straw b) sorghum

Figure 2 shows thethree-dimensional graphs of the response surface of the total phenolic content values of corn straw and sorghum extracts against temperature, solvent volume and extraction time. When the total phenolic content value of corn straw extract was examined in terms of solvent volume and temperature factors, it was observed that the TPC value increased with increasing the amount of solvent, while the temperature was around $80{ }^{\circ} \mathrm{C}$ (Fig 2.a.x). Some studies have shown that TPC values are lost because high temperatures damage the phenolic components [9-11]. The reason is explained by Prasad et al. (2011) as follow; the dielectric constant of the water at high temperature decreases and the solvent property changes and the phenolic substances can be extracted better [12]. High temperature also increases the solubility of phenolic substances, diffusion rate, extraction rate, decreases solvent viscosity and surface tension. However, high extraction temperatures can also lead to undesired results. For instance, degredation of phenolic substances arising from chemical and 
enzymatic degradation or a reduction in total phenolic content is increased by the increase of the extraction temperature.

When the relationship between the extraction time and temperature were examined at a constant solvent volume, it was observed that the TPC was increasedwith an increasing of these two factors (Fig 2.a.y). Although TPC value of corn straw extract at a constant temperature increased with increasing solvent volume while extraction time did not change significantly (Fig 2.a.z). We have also examined the relation between solvent volume, extraction time and temperature on the value of total phenolic content of sorghum extract. The results showed that the TPC value increased while the amount of solvent and temperature increased at a constant extraction time (Fig. 2.b.x) On the other hand, we have found no significant effect of the extraction time on the TPC value while temperature increases (Fig.2.b.y).When we questioned the effect of solvent volume and extraction time, it was found that TPC value increased with increasing in amount of solvent and decreased with the increase in the extraction time (Fig.2.b.z). Some of the phenolic compounds are water-soluble, some are soluble in organic solvents and some are large insoluble polymers. For this reason, instead of using single solvent, a solvent with water and organic solvent mixture was used. The structure and composition of the material used, the type of heat treatment applied and the degree of temperature can lead to an increase in the amount of phenolic compounds [13]. It was seen that different results were obtained because of structural differences between corn straw and sorghum.

\subsection{Model equation for antioxidant activity (BHT)}

The equations of the model obtained as a result of the studies performed for the antioxidant activities of corn straw and sorghum extracts are given below;

Antioxidant activity (corn straw) $\mathrm{y}=+2.42-0.083 \mathrm{~A}+0.67 \mathrm{~B}+0.054 \mathrm{C}+7.500 \times 10^{-003} \mathrm{AB}-$ $0.24 \mathrm{AC}+0.39 \mathrm{BC}+0.069 \mathrm{~A}^{2}-0.23 \mathrm{~B}^{2}+0.12 \mathrm{C}^{2}$ (Eq.5)

Antioxidant activity (sorghum) $\mathrm{y}=+16.64-0.61 \mathrm{~A}+2.76 \mathrm{~B}-0.031 \mathrm{C}-0.022 \mathrm{AB}-$ $2.06 \mathrm{AC}+4.02 \mathrm{BC}-7.31 \mathrm{~A}^{2}-2.64 \mathrm{~B}^{2}-1.06 \mathrm{C}^{2}$ (Eq.6)

The $\mathrm{R}^{2}$ and $\mathrm{R}_{\text {adj }}$ values of antioxidant activities models of corn and sorghum extracts were 0.9415 ve 0.8361 for corn straw and 0.9068 ve 0.7390 for sorghum, respectively. Where $\mathrm{R}^{2}$ is greater than $90 \%$, the independent variables (temperature, solvent amount and extraction time) indicate that the value of antioxidant activity (BHT) is qualifiable. The effects of solvent amount on the antioxidant activity values of corn straw and sorghum extracts were statistically significant. Solvent type and polarity are effective on single electron transfer and hydrogen atom transfer which are important in measuring antioxidant capacity [14].There are different solvents used in the literature for antioxidant extraction. Solvents generally used in the extraction of medicinal herbs include methanol, ethanol, acetone, petroleum ether, hexane and their different concentrations.

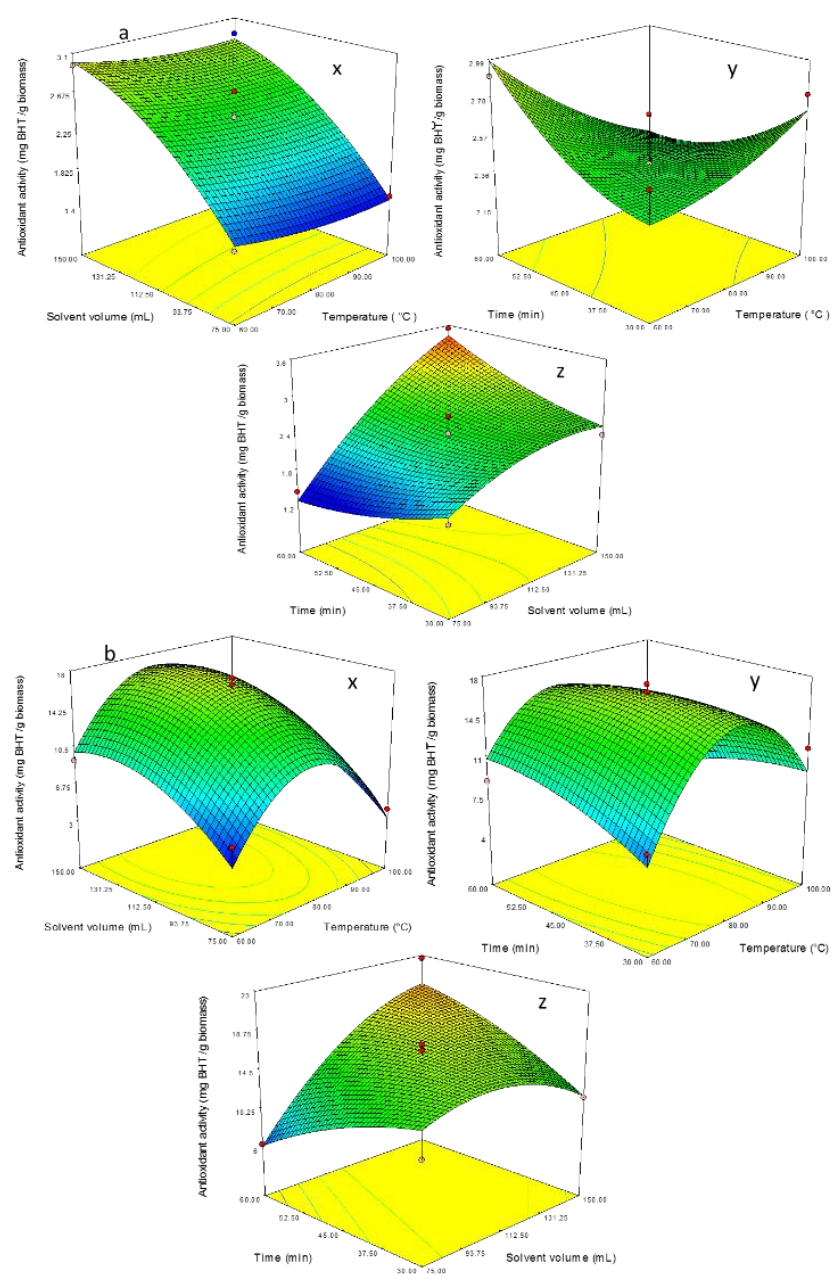

Fig. 3. Response surface graphs for antioxidant activity a ) corn straw b) sorghum

Figure 3 shows the three-dimensional graphs of the response surface of theantioxidant activity values of corn straw and sorghum extracts against temperature, solvent amount and extraction time. When the antioxidant activity values of corn straw extracts were examined against the amount of temperature and solvent, antioxidant activity was directly affected by the amount of solvent (Fig 3.a.x). The change in temperature did not significantly affect the result. It can be said that the increase in the extraction time increases the antioxidant activity and decreases with the increase in temperature (Fig 3.a.y). According to Fig 3.a.z, the extraction time and the amount of solvent 
had a positive effect on the antioxidant activity. The degree and time of the applied temperature can change the antioxidant properties (Calligaris ve ark., 2004). The Eq. 5 and Eq. 6 of antioxidant activities models of corn and sorghum extracts showed that the temperature has a negative effect on antioxidant activity.

This disparity may be attributed to differences in antioxidant capacity of phenolics. All phenolic compounds do not have same antioxidant capacity, for example tannins are known to have higher antioxidant activity as compared to other simple phenolics so increasing temperature not always resulted with increasing antioxidant capacity of extract despite of high levels of phenolics [15].

Some phenolic compounds and antioxidants can be destroyed and reduced by thermal treatment. In general, it is expected to decrease the amount of antioxidant activity and total phenolic content by thermal treatment [16]. Whenthe surface graphs of the antioxidant activity for sorghum extracts were viewed, it was seen that the antioxidant activity increased to 80 ${ }^{\circ} \mathrm{C}$ and then started to decrease in Fig 3.b.x and Fig 3.b.y. Similar results have been found in other literature studies [17-20].

\subsection{Verification experiments}

The verification experiments were carried out using recommended optimal conditions derived from analysis of RSM for the factors; extraction temperature, extraction time and solvent volume. The experimental results were reasonably close to the predicted values verifying the validity of the RSM model (Table 3). The optimum extraction conditions to obtain high antioxidant yields with high antioxidant activities within the extraction parameters were: $77^{\circ} \mathrm{C}$ (temperature), $150.0 \mathrm{~mL}$ (solvent volume), $60 \mathrm{~min}$ (time) and $90{ }^{\circ} \mathrm{C}$ (temperature), $150.0 \mathrm{~mL}$ (solvent) 50 min (time) for corn straw and sorghum, respectively. As shown in Table 5, predicted and experimental results were in harmony with each other. Therefore, it is suggested the models obtained can be used to optimise the process of antioxidant bioactive compounds extraction from lignocellulosics.

Table 5.The extraction yield, total phenol content and antioxidant activity found in recommended optimal conditions for corn straw and sorghum

\begin{tabular}{lcccc}
\hline Responses & \multicolumn{2}{c}{ Corn Straw } & \multicolumn{2}{c}{ Sorghum } \\
& Predicted & Experimental & Predicted & Experimental \\
Extraction Yield (\%) & 15.39 & $14.31 \pm 1.32$ & 18.45 & $19.49 \pm 1.55$ \\
TPC (mg gallic acid/g biomass) & 5.08 & $4.32 \pm 0.28$ & 8.60 & $8.59 \pm 0.32$ \\
Antioxidant activity & 3.46 & $2.40 \pm 1.43$ & 15.70 & $13.74 \pm 2.14$ \\
(mg BHT /g biomass) & & & & \\
\hline
\end{tabular}

\section{Conclusions}

This study was designed to optimize extraction parametres on extraction yield, total phenol content and antioxidant activity from lignocellulosic biomass. A 3-factor and 3-level Box-Behnken design was applied to understand the effect extraction parametres (temperature, solvent volume and extractiom time). The results showed that the extraction temperature was the main positive linear effect on extraction yield, the solvent volume and temperature were significant terms on total phenol content and the solvent amount has a linear positive effect for sorghum while it has quadratic effect for corn straw on antioxidant activity. The optimization model has been developed for the highest percentage of extraction, total phenol content and antioxidant activity. It was observed that recommended optimal conditions were in harmony with each other. With this study, it is thought that a standard for extraction of antioxidant plants which have an important place in the field of medicine and pharmacy can be developed by using RSM.

\section{Conflicts of interest}

The authors state that did not have conflict of interests

\section{References}

[1] Hall, III.C. :Source of natural antioxidants: oilseeds, nuts, cereals, legumes, animal products and microbial sources. Antioxidants in Food, Practical Applications, J Pokorny, N Yanislhlieva and $\mathrm{M}$ Gordon (eds), Cambridge: Woodhead Publishing Ltd., 2001; pp 169-219 .

[2] Balasundram N., Sundram, K., Samman. S., Phenolic compounds in plants and agri-industrial by-products: Antioxidant activity, occurrence, and potential uses, Food Chem., 99 (2006) 191203.

[3] Glasser W. G., Thermochemical biomass conversion processes are aimed for bio-fuels. In: Fundamentals of thermochemical biomass conversion, R. P. Overand, T. A. Mile, and L. K. 
Mudge (Eds.), New York: Elsevier Applied Science Publisher, 1985.

[4] Icten O., Hydrogen Production from Sorghum by Aqueous Phase Reforming Process, Çukurova University, Master thesis, (2011).

[5] Cardoso L.M., Montini T.A., Pinheiro S.S., Pinheiro-Sant'Ana H.M., Martino H.S.D., Moreira, A.V.B., Effects of processing with dry heat and wet heat on the antioxidant profile of sorghum, Food Chem., 152 (2014) 210-217.

[6] Liu H., Ou X., Yuan J., Yan X., Experience of producing natural gas from corn straw in China., Resour Conserv Recy., 135 (2018) 216-224.

[7] Caboni E., Tonelli M.G., Lauri P., Lacovacci P., Kevers C., Damiano C., Gaspar T., Biochemical aspects of almond microcuttings related to in vitro rooting ability, Biol. Plant., 39 (1997) 91-97.

[8] Prior R.L, Wu X., Schaich K., Standardized methods for the determination of antioxidant capacity and phenolics in foods and dietary supplements, J Agr Food Chem., 53 (2005) 42904610.

[9] Sun Y., Xu W., Zhang W., Hu Q., Zeng X., Optimizing the extractionof phenolic antioxidants fromkudingchamade frrom Ilex kudingcha C.J. Tseng by using response surface methodology, Sep PurifTechnol., 78 (2011) 311-320.

[10] Ballard T.S., Mallikarjunan P., Zhou K., O’Keefe S.F., Optimizing the extraction of phenolic antioxidants frompeanut skins using response surface methodology, J Agr Food Chem., 57 (2009) 3064-3072.

[11] Cacace J., Mazza G., Optimization of extraction of anthocyanins from black currants with aqueous ethanol, J Food Sci., 68(2003) 240-248.

[12] Prasad K.N., Hassan F.A., Yang B., Kong K.W., Ramanan R.N., Azlan A., Ismail A.,Response surface optimisation for the extraction of phenolic compounds and antioxidant capacities of underutilised Mangifera pajang Kosterm. Peels, Food Chem., 128 (2011) 1121-1127.

[13] Sakac M., Torbica A., Sedej I., Hadnadev M., Influence of breadmaking on antioxidant capacity of gluten free breads based on rice and buckwheat flours, Food Res. Int., 44 (2011) 2806-2813.

[14] Perez-Jim ' enez J. and Saura-Calixto F., Effect of solvent and certain food constituents on different antioxidant capacity assays, Food Res. Int., 39 (2006) 791-800.

[15] Dlamini N.R., Taylor J.R.N., Roon L.W., The effect of sorghum type and processing on the antioxidant properties of African sorghum-based foods, Food Chem., 105 (2007) 1412-1419.

[16] Raciye Meral., The Effects of Different Thermal Applications on Phenolics Compounds, Yüzüncü Y1l University, Journal of The Institute of Natural \& Applied Sciences 21 (2016) 55-67.

[17] Calligaris S., Manzocco L., Anese M., Nicoli M.C., Effect of heat-treatment on the antioxidant and pro-oxidant activity of milk, Int. Dairy. J., 14 (2004) 421-427.

[18] Choi Y., Lee S.M., Chun J., Lee H.B., Lee J., Influence of heat treatment on the antioxidant activities and polyphenolic compounds of Shiitake (Lentinus edodes) mushroom, Food Chem., 99(2006) 381-387.

[19] Grupta V., Nagar R., Effect of cooking, fermentation, dehulling and utensils on antioxidants present in pearl millet rabadi-a traditional fermented food, J.Food.Sci. Technol., 47 (2010) 73-76.

[20] Kim S.Y., Jeong S.M., Park W.P., Nam K.C., Ahna D.U., Lee S.C., Effect of heating conditions of grape seeds on the antioxidant activity of grape seed extract, Food Chem., 97 (2006) 472-479. 